\title{
La saturación de eclesiásticos en la Lima barroca
}

In: Caravelle, n6-77, 2001. Hommage à Georges Baudot. pp. 255-263.

Citer ce document / Cite this document :

Serrera Ramón María. La saturación de eclesiásticos en la Lima barroca. In: Caravelle, n76-77, 2001. Hommage à Georges Baudot. pp. 255-263.

doi : $10.3406 /$ carav.2001.1303

http://www.persee.fr/web/revues/home/prescript/article/carav_1147-6753_2001_num_76_1_1303 


\section{Résumé}

RÉSUMÉ- Le nombre excessif et croissant des monastères et couvents dans les territoires espagnols des deux rives de l'océan, aux XVIle et XVIIle siècles, étaient déjà un fait évident, dénoncé par beaucoup et vainement combattu par la Couronne, dans le Lima du XVIle siècle naissant. Les monastères et couvents s'emplissaient de religieux sans vocation, qu'entouraient de nombreux serviteurs. La cause principale en était l'incapacité où se trouvait l'élite de tenir son rang avec des familles nombreuses. Les arbritistas dénonçaient le danger de dépeuplement et, avec plus de clairvoyance, le risque de voir la richesse de la vice-royauté tomber sous la coupe des ecclésiastiques.

\section{Abstract}

ABSTRACT- The excesive and constantly increasing amount of monasteries and covents in the Spanish territories on both sides of the ocean, during the 17th and 18th centuries, was already an evident fact, denounced by many and uselessly attacked by the Crown in Lima, at the beginning of the 17C century. The monasteries and convents were filled by monks with no religious vocation and surrounded by many servants. The main cause was the imposibility for the ruling classes to maintain their social position when they had large families. The arbitristas denounced the danger of depopulation and, with even more clearsightedness, the risk that the Viceroyalty's wealth should fall into the hands of the clergy.

\section{Resumen}

RESUMEN- El número excesivo y creciente de monasterios y conventos en todos los reinos españoles de ambas orillas del océano en los siglos XVII y XVIII, era ya un hecho evidente, denunciado por muchos y combatido inútilmente por la Corona en la Lima de principios del XVII. Las clausuras se llenaban de monjes y monjas sin vocación, rodeados de una numerosa servidumbre. El motivo principal radicaba en la incapacidad de las élites criollas para mantener el decoro de familias numerosas. Los arbitristas denunciaban el peligro de despoblación y, con más acierto, el riesgo de que la riqueza del virreinato quedara entre las manos de los clérigos.

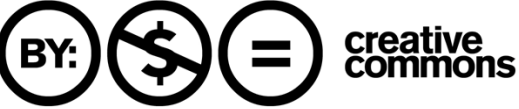




\title{
La saturación de eclesiásticos en la Lima barroca
}

\author{
PAR \\ Ramón María SERRERA \\ Universidad de Sevilla
}

A partir de la segunda década del siglo XVII las autoridades indianas comenzaron a denunciar que en el Nuevo Mundo, y más concretamente en el Perú, sobraban personas consagradas al servicio de la Iglesia. Si se admite como válida para los años centrales del siglo XVII la cifra de 11.000 o 13.0000 eclesiásticos en Indias, de los que apenas 2.000 se adscribían al clero regular, hay que admitir que la proporción resultaba ciertamente elevada. ${ }^{1}$ En una época en la que la Iglesia ofrecía un claro cauce de promoción social y cultural, las órdenes religiosas, sin abandonar sus tareas estrictamente misionales en el medio rural, se van a replegar hacia los principales centros urbanos. En este nuevo escenario encuentran una nueva clientela espiritual materialmente más rentable compuesta por funcionarios, comerciantes, mineros, hacendados y encomenderos que, en vida o al dictar su última voluntad en el lecho de muerte, donan a las distintas órdenes regulares cuantiosas propiedades y rentas rústicas o urbanas para sufragar sus cultos o sus actividades religiosas. 2

El problema de la proliferación de conventos y monasterios masculinos y femeninos, y el asombroso incremento del número de personas consagradas que vivían en sus clausuras, empieza a detectarse en la correspondencia de las autoridades civiles y eclesiásticas desde los primeros años del siglo XVII, aunque se fue acentuando conforme avanzaba la centuria. El caso de Lima llegó a ser proverbial. Todos los

1 Serrera, "Las Indias Españolas en el siglo XVII", cap. 4 de Descubrimiento, colonización y emancipación de América, tomo 8 de la Historia de España dirigida por Antonio Domínguez Ortiz, Barcelona, Ariel-Planeta, 1990, p. 400.

2 Ibidem, p. 403 y $445-453$. 
viajeros refieren que la presencia de frailes y clérigos era consustancial a la escenografía urbana de la capital virreinal. A pesar de que un breve pontificio de 1611 de Pablo V ordenó suspender la actividad de todos los conventos que contaran con menos de ocho frailes residentes, la medida no se cumplió. El franciscano fray Buenaventura de Salinas y Córdova, en su obra De los Méritos y Excelencias de la Ciudad de Lima, de 1630, apunta que el padrón de la capital peruana de 1614 del virrey marqués de Montesclaros arrojó como resultado un total de 25.454 personas residentes, de las cuales 894 eran frailes, 820 religiosas, 300 clérigos diocesanos (sin contar "los que tiene la Iglesia Mayor») y 425 personas "en el servicio de las monjas», sin contar otras mujeres en centros de recogidas. En total, 2.439 personas viviendo en los conventos o adscritas al estado eclesiástico, casi un $10 \%$ de la población total de la Ciudad de los Reyes. ${ }^{3}$ Cuando escribe el franciscano, la población limeña se había elevado ya a "más de cuarenta mil personas», 4 con paralelo aumento del número de eclesiásticos.

En comparación con la Metrópoli, y en relación con la población total, puede afirmarse que en España hubo siempre más número de conventos, aunque en Indias era más elevada la cifra media de los residentes en sus clausuras. Domínguez Ortiz ofrece noticias de 1623 que sugieren que los conventos de hombres y los monasterios de monjas «en toda la extensión de España" sumaban 2.141 casas, con 44.915 religiosos y religiosas. De 1738 hay estimaciones de 2.104 conventos masculinos y 976 de religiosas. Y de 1787, unos años después de la expulsión de la Compañía de Jesús, 2.067 conventos de frailes con 52.300 moradores y 1.122 de monjas con 25.365 mujeres en sus clausuras. 5 Había ciudades españolas con una muy alta concentración de conventos y monasterios distribuidos en su traza urbana. Según el propio Domínguez Ortiz, en el siglo XVII Alcalá de Henares llegó a tener 27 conventos, Segovia 24, Toro 14, Medina del Campo 15, Salamanca 31 y Valladolid 46. Madrid pasó, de tener 25 conventos de frailes (con 1.062 religiosos) y 20 de monjas (con 943 mujeres) en el año 1567, a un total de 69 casas un siglo después, 6 y 44 conventos religiosos (con 2.443 frailes) y 31 de religiosas

3 Buenaventura de Salinas y Córdova, O.F.M., Memorial de las Historias del Nuevo Mundo. Pirv. Introducción de Luis E. Valcárcel y estudio preliminar de Warren L. Cook, Lima, Universidad Nacional Mayor de San Marcos, 1957, Discurso II, De los méritos y excelencias de la Ciudad de Lima, cap. VI "El número y condición de los vecinos y pobladores de la Ciudad de Lima...", p. 245.

4 Ibidem, p. 246. Textualmente afirma que uestos números de gentes han crecido en grande exceso, y se van aumentando cada día".

5 Antonio Domínguez. Ortiz, La sociedad española en el siglo XVII (edición facsímil). Estudio preliminar del autor con bibliografía y reseñas de Antonio Luis Cortés Peña, Granada, Servicio de Publicaciones de la Universidad de Granada, 1992, vol. II, El estamento eclesiástico, p. 70.

6 Ibidem, p. 78. 
(con 869 monjas) en el reinado de Carlos III.7 La evolución del número total de conventos (45 en la época de Felipe II, 69 en el reinado de Carlos II y 76 en el de Carlos III) resulta clara. Y otro tanto aconteció en Sevilla, "puerto y puerta de las Indias". En 1581 contaba con 19 centros de varones y otros tantos de monjas, que en 1671 se habían convertido en 45 y 18 respectivamente. 8

Nada tiene de extraño, pues, que en una real cédula de 1620 dirigida al virrey príncipe de Esquilache se aludiera a que, "siendo esa ciudad de tan corta vecindad, tengo entendido que hay en ella tanto número de conventos que parece que esta parte es mayor que el todo». Aunque el cálculo pueda resultar exagerado, era lo que por entonces se pensaba en Madrid. Años más tarde, en otra disposición regia de 1653, cuyo destinatario era esta vez el cabildo catedralicio de Lima, se insistía de nuevo en el tema al indicar que «se ha representado que el número de conventos es muy grande", y cada uno "con cantidad considerable de religiosos, habiendo ciudades donde hay tres partes más que de vecinos».9 En 1660, el arzobispo de Lima, don Pedro Villagómez, indicaba escandalizado que, después de haber recorrido su diócesis en visita pastoral, comprobó que en ella existían 180 parroquias y doctrinas; pero que, frente a los 300 clérigos que residían en Lima, sólo se contaba con unos 200 para el resto del obispado. ${ }^{10} \mathrm{Y}$ justo un año después, en 1661, el virrey conde de Santisteban llegó a afirmar que "sobran frailes en los conventos y faltan en las doctrinasm.11

El ingeniero militar francés Amadeo Frezier, que conoció Lima en 1713, llega a insinuar que la capital virreinal peruana era una ciudad conventualizada, con «legiones de religiosos cuyas casas han acaparado la parte más bella y más grande de la ciudad».12 En su recuento de

7 "Madrid en la mano", hoja manuscrita sin fechar con indicación de datos de la "Regulación matricular" de la Villa y Corte correspondientes al reinado de Carlos III: parroquias, conventos, hospitales, colegios, casas, vecinos, personas, cárceles, calles, plazas, cuarteles, manzanas, etc. Toda la información está incluida en recuadros distribuidos en las ramas de un frondoso árbol dibujado a tinta. Biblioteca particular del autor de estas líneas.

8 Domínguez Ortiz, El estamento eclesiástico, p. 78.

9 Real cédula de 18 de septiembre de 1653 dirigida al deán y cabildo catedralicio de Lima. Archivo General de Indias (A.G.I.), Lima 60. Hemos abordado el tema más extensamente en Ramón María Serrera, "El trabajo indígena como soporte económico de la fundación del Colegio de la Merced de Lima (siglo XVII)", Gades, Revista del Colegio Universitario de Cádiz, n 1,1978 , p. 58 y ss.

10 Antonio de Egaña, S.I., Historia de la Iglesia en la América Española desde el Descubrimiento hasta comienzos del siglo XIX, Hemisferio Sur, Madrid, Biblioteca de Autores Cristianos, 1966, p. 295.

11 Ibidem, p. 296 y Serrera, El Colegio de la Merced de Lima, p. 59.

12 Amadeo Frezier, Relación del viaje por el Mar del Sur. Prólogo de Gregorio Weinberg, traducción, notas y cronología de Miguel A. Guerin, Caracas, Biblioteca Ayacucho, 1982, p. 198. La cursiva es nuestra. Hay un espléndido estudio sobre el periplo de Frezier por el 
instituciones eclesiásticas limeñas aparecen 8 parroquias, 14 hospitales, 25 conventos masculinos y 12 fememinos, estos litimos con más de 4.000 monjas. 13 Le llamó poderosamente la atención el Convento Grande de San Francisco, con 700 hombres entre religiosos y domésticos, y los cuatro centros agustinos, que «albergan más de quinientos religiosos». 14

Ya en las décadas finales del XVII este problema de la saturación de conventos y de religiosos había alcanzado unas proporciones incontroladas. De ello se percató con claridad un buen conocedor de la realidad indiana, don Gabriel Fernández de Villalobos, marqués de Varinas, en su extenso Estado Eclesiástico, Político y Militar de la América, escrito en torno a 1683, en cuyo capítulo 52, dedicado a los «Frailes y monjas del Perú y Nueva España», daba de nuevo el grito de alarma sobre el tema con estas significativas palabras:

La muchedumbre de conventos de religiosos y religiosas que hay se van apoderando de lo más florido, fructífero y cuantioso de las haciendas de todas las Indias; de suerte que hay ciudad en donde las cuatro partes de hacienda que tiene, las tres son rentas eclesiásticas. 15

Los propios cronistas e informantes del siglo XVII intentaban explicar las razones de este fenómeno. En el caso ya citado de Fern.ndez de Villalobos, derivaba del hecho de que

como en aquellas partes las educaciones de las familias son algo más libres por los naturales e inclinaciones de aquellos climas, los padres, por excluirse de aquel cuidado, aplican todos los más hijos que tienen, así hombres como mujeres, a las religiones; y como éstos no llevan la vocación que requiere para tan perfecto estado y los arrastra el natural, pocos salen cuales debían ser. Y se pueblan los conventos y monasterios de ociocidades que acarrea consigo los vicios que en uno y otro sexo se deja entender. 16

Destacaron en cifras absolutas las grandes fundaciones de las dos cortes virreinales, Lima y México; pero el fenómeno se generalizó igualmente a lo largo y ancho de todas las Indias, con casos significativos como Puebla, Quito, La Plata, Potosí, Santa Fe de Bogotá, Tunja,

Nuevo Mundo. Se trata de la obra de Luisa Vila Vilar, El viaje de Amedée Frézier por la América Merdional, Sevilla, Excma. Diputación Provincial de Sevilla, 1991, 385 p. Para el tema que nos ocupa en el texto, remitimos particularmente al capítulo $\mathrm{V}$, dedicado a "La Iglesia y los eclesiásticos", p. 157-186.

13 Frezier, Relación, p. 200.

14 Ibidem, p. 199.

15 Gabricl Fernández de Villalobos (Marqués de Varinas), Estado Eclesiástico, Político y Militar de la América (o Grandeza de Indias). Estudio preliminar y edición de Javier Falcón Ramírez, Madrid, Instituto de Cooperación Iberoamericana-Instituto de Estudios Fiscales, 1990, p. 547.

16 Ibidem, p. 547 y 548 . 
Santiago de Chile, Querétaro, Guatemala, Arequipa, etc., e incluso en ciudades de segundo o tercer orden que contaban con tres o cuatro monasterios masculinos y femeninos. $17 \mathrm{El}$ código de valores de aquella jerarquizada, cerrada y elitista sociedad barroca colonial orientaba hacia el convento a un amplio sector de la juventud, sobre todos muchachas, que por razones económicas familiares no podían llegar al matrimonio con dote y futuro esposo acordes con su rango.18 Como apuntó en $1983 \mathrm{el}$ recordado José Francisco de la Peña, mientras mayor fuera la desigualdad social entre los contrayentes, más elevada había de ser la cantidad entregada por los padres de la joven en calidad de dote. En términos coloquiales podríamos decir que resultaba menos costoso dotarla para su entrada en religión que para el estado de casada. Y más, en el caso -muy frecuente por cierto- de la clásica familia numerosa del español en Indias. 19

Al estudiar Domínguez Ortiz las órdenes femeninas en España en el siglo XVII, con su habitual ponderación llega a expresar que para muchos miembros de los grupos medios y de la nobleza inferior el problema de colocar a sus hijas "se hizo angustioso" cuando se generalizó la costumbre de exigir crecidas dotes tanto para contraer matrimonio como para profesar en religión. A su juicio, los casos de muchachas materialmente obligadas por sus padres a entrar en el convento eran reales, aunque no tan numerosos como se afirmaba en la época. Al respecto, el propio autor cita un testimonio clarificador del año 1574 de fray Hernando del Castillo, quien, al tratar de las religiosas, claramente apunta que éstas procedían en «una grandísima parte de la nobleza de España, adonde los grandes señores y toda la gente ilustre que no puede casar de seis ni de cuatro hijas más que una, y para el remedio de ésta, por ser las dotes excesivas van las otras hermanas a los monasterios compelidas por la necesidad».20

17 Remitimos al lector a dos espléndidos estudios: el de Kathleen Ann Myers, "Las monjas y la identidad criolla en Nueva España: un caso ejemplar de la fundación de conventos", El Paraíso Occidental. Norma y diversidad en el México Virreinal, Salvador Bernabéu Albert (coord), Madrid, Instituto de México en España, 1998, p. 93-120; y el de Pilar Gonzalbo, Las mujeres en la Nueva España: educación y vida cotidiana, México, El Colegio de México, 1987. Véase también el clásico trabajo de Josefina Muriel, Conventos de monjas en la Nueva España, México, Editorial Santiago, 1946.

18 Serrera, Las Indias Españolas en el siglo XVII, p. 403 y 404.

19 José F. de la Peña, Oligarquía y propiedad en Nueva España, 1550-1624. México, Fondo de Cultura Económica, 1983, p. 190 y 191.

20 Domínguez Ortiz, El estamento eclesiástico, p. 114 . Véase el estudio sobre el tema de Luis Martín, Daughters of the Conquistadores: Women of the Viceroyalty of Peru, Alburquerque, University of New Mexico Pressa, 1983; y la importante aportación de Asunción Lavrin, "Female Religious", Cities and Society in Colonial Latin America, Louisa S. Hoberman y Susan M. Socolow edit., Alburquerque, University of New Mexico Press, 1986, p. 165-196. 
El fenómeno, como podemos observar, no era exclusivo de las ciudades indianas. El mismo código de valores e idénticas claves culturales operaban en el seno de los grupos medios y acomodados de la sociedad española a una y otra orilla del Atlántico.21

El convento femenino se convirtió ya desde los años finales del XVI en un refugio y válvula de escape ante la imposibilidad de vivir en el mundo con el lustre y dignidad requeridos por el rango familiar de la monja que profesaba en religión. Muy gráficamente explica esta realidad en los años setenta del siglo XVII el fraile carmelita fray Isidoro de la Asunción, visitador de su orden en Nueva España, al referir que «como el gasto es tan grande en las Indias y la pobreza mucha, son pocos los que pueden sustentar mujer y familia; y por la misma razón son muchísimas las monjas y criadas que viven en los conventos». 22 Pero el fenómeno se apreció desde mucho antes, ya en los años iniciales de la centuria, en Lima. Lo atestigua el judío portugués Pedro de León Portocarrero,23 autor de la Descripción del Virreinato del Perú, de la primera década del XVII. Coincide fundamentalmente con el carmelita al referir que

como los criollos son poco aficionados al trabajo, son muy desvanecidos en esto de la hidalguía; y así, se dan mucho al estudio y se hacen frailes y clérigos, y las criollas se meten monjas. Muchas de cllas, que como en el convento tienen la comida y el vestido seguro, no se quieren aventurar ni ponerse en peligro por mar ni tierra para ganar la vida. 24

Sucesivas disposiciones regias dictadas a lo largo del siglo XVII con la finalidad de limitar el número de nuevas fundaciones tuvieron escaso eco. Particularmente frecuentes fueron en las dos primeras décadas (1598, $1607,1608,1617,1618$, etc.), que es cuando los virreyes comenzaron a alertar al Monarca sobre la gravedad del problema. Pero fueron incumplidas sistemáticamente. En los años centrales de la centuria tuvo la Corona que radicalizar sus posiciones al respecto disponiendo la suspensión de nuevas fundaciones o clausurando -a veces con orden

21 Véase la obra de mi alumna María del Carmen Rodríguez Duarte, El convento de Regina Coeli: un modelo de vida monástica en la Sanlúcar del Barroco. Sanlúcar de Barrameda, Excmo. Ayuntamiento de Sanlúcar de Barrameda, Delegación del Cultura, 1998. Como obra de referencia general, remitimos al lector al estudio magistral que ofrece José Luis Sánchez Lora en su monografía Mujeres, conventos y formas de religiosidad barroca, Madrid, Fundación Universitaria Española, 1988.

22 María Josefa Arnall Juan, "El Itinerario a Indias (1673-1679) del P. Fr. Isidoro de la Asunción, C.D. (Manuscrito 514 de la Biblioteca Provincial y Universitaria de Barcelona)", Boletín Americanista, Universidad de Barcelona, año XX, $n^{\circ} 28,1978$, p. 223.

23 Guillermo Lohmann Villena, "Una incógnita despejada: la identidad del judío portugués autor de la Discriçión del Pirú". Revista de Indias, XXX, Madrid, 1970, n. 119 122, p. 315-388.

24 Descripción del Virreinato del Perú. Crónica inédita de comienzos del siglo XVII. Edición, prólogo y notas de Boleslao Lewin, Rosario, 1958, p. 74. 
terminante de demolición- algunos de los conventos y colegios ya existentes que funcionaban sin autorización regia.25 En su extenso memorial de 1683, el marqués de Varinas llegó a proponer al Rey como remedio que gestionara ante la Santa Sede una bula en la que se dispusiera, entre otros puntos,

que en 16 años no entren ni admitan en los conventos de las Indias religiosos ningunos, ni en los conventos de monjas, porque son tantos que es el número infinito... que no reciban en adelante tantos como solían, sino que los pocos que en adelante entraren sean escogidos y gente de lustre. Y no como se ha hecho hasta aquí, que toda la gente ruin, viendo que en el siglo no podían tener estimación ni lugar ninguno entre los seculares, se aplicaban a las religiones. 26

El problema, para Fernández Villalobos, resultaba particularmente grave en el caso de los conventos de monjas, con directas implicaciones en el -a su juicio- secular problema del despoblamiento de las Indias, un tema que preocupó a los arbitristas del XVII tanto en España como en el Nuevo Mundo. Según afirma,

lo que pasa en estos monasterios de tener cada religiosa seis o siete criadas para servirse... es contra el estatuto de su regla en deservicio de Dios por lo que pasa allí dentro; y aún de V.M. en que aquellas criadas estén encerradas, porque se impide la multiplicación y población de las Indias... habiendo conventos de monjas que tiene 600 criadas seglares en México y Lima y otras partes; al respecto vea V.M. si harán falta a la población de aquel reino. 27

La otra vertiente que aborda el marqués de Varinas es la económica. Nuestro analista critica el hecho de que los conventos femeninos se hubieran convertido en grandes centros financieros que contaban con numerosos recursos disponibles en metálico para financiar el crédito de los particulares. $28 \mathrm{Y}$ acerca de la acumulación de propiedades rústicas y urbanas en manos eclesiásticas llega a sugerirle al Rey que

si no lo remedia V.M., antes de 40 años no habrá hacienda de sementera, hato de ganado, casa, viña, ingenio de azúcar y obraje que no sea de

25 Hemos abordado el tema más extensamente en Serrera, La fundación del Colegio de la Merced de Lima, p. 60 y ss.

26 Fernández de Villalobos, Estado Eclesiástico, p. 555 y 556. La cursiva es nuestra.

27 Ibidem, p. 556.

28 Ramón María Serrera, «El Convento de la Concepción de Caracas y el crédito agrario en el nacimiento de la economía del cacao en Veneziuela (s. XVII)". Actas del I Congreso Internacional de la Orden Concepcionista, León, 1990, vol.I, 537-554; y Asunción Lavrin, "Women in Convents: Their Economic and Social Role in Colonial México", Liberating Women's History, Benerice A. Carrol (edit.), Urbana, University of Illinois Press, 1976, p. 249-277. 
eclesiástico 29 , con que los seculares no vendrán a tener en las Indias nada, viniendo a gran miseria todo el reino. 30

Es mucho más profundo de lo que parece el an.lisis de nuestro arbitrista, porque llega a las mismas conclusiones que la historiografía americanista de las últimas décadas, sobre todo en lo referente al control de una gran parte del circulante monetario indiano por parte de las órdenes regulares ("el recoger toda la plata que hay en el Reino") y el progresivo endeudamiento del sector privado a través de censos (otorgado siempre con garantía hipotecaria) en favor de iglesias, fundaciones y monasterios, porque -como expresa Fernández Villalobos- al ser éstos «los que tienen la grosedad de todas las haciendas, los españoles sólo son unos feudatarios que les están contribuyendo todo el añon.31 La misma observación haría treinta años después el ingeniero militar francés Amadeo Frezier en su espléndida descripción de la ciudad de Lima en 1713 al referir que este abuso, según todas las apariencias, perdurará, y al cabo de poco tiempo los seglares se hallarán más dependientes de las comunidades en lo temporal de lo que están en lo espiritual.32

RESUMEN- El número excesivo y creciente de monasterios y conventos en todos los reinos españoles de ambas orillas del océano en los siglos XVII y XVIII, era ya un hecho evidente, denunciado por muchos y combatido inútilmente por la Corona en la Lima de principios del XVII. Las clausuras se llenaban de monjes $y$ monjas sin vocación, rodeados de una numerosa servidumbre. El motivo principal radicaba en la incapacidad de las élites criollas para mantener el decoro de familias numerosas. Los arbitristas denunciaban el peligro de despoblación y, con más acierto, el riesgo de que la riqueza del virreinato quedara entre las manos de los clérigos.

29 Casi en los mismos términos se expresa el arzobispo de Lima don Pedro Villagómez al Rey en carta fechada en Lima, 11 de junio de 1647, A.G.I., Lima 339. Y la misma opinión era compartida por otros coetáneos, tanto en Perú como en otras provincias indianas. Hemos tratado el tema en Serrera, El Colegio de la Merced de Lima, p. 69-71.

30 Fernández de Villalobos, Estado Eclesiástico, p. 557.

31 Ibidem, p. 558.

32 Frezier, Relación, p. 210. 
RESUMÉ- Le nombre excessif et croissant des monastères et couvents dans les territoires espagnols des deux rives de l'océan, aux XVII et XVIII e siècles, étaient déjà un fait évident, dénoncé par beaucoup et vainement combattu par la Couronne, dans le Lima du XVIre siècle naissant. Les monastères et couvents s'emplissaient de religieux sans vocation, qu'entouraient de nombreux serviteurs. La cause principale en était l'incapacité où se trouvait l'élite de tenir son rang avec des familles nombreuses. Les arbritistas dénonçaient le danger de dépeuplement et, avec plus de clairvoyance, le risque de voir la richesse de la vice-royauté tomber sous la coupe des ecclésiastiques.

ABSTRACT - The excesive and constantly increasing amount of monasteries and covents in the spanish territories on both sides of the ocean, during the $17^{\text {th }}$ and $18^{\text {th }}$ centuries, was already an evident fact, denounced by many and uselessly attacked by the Crown in Lima, at the beginning of the $17^{\text {th }}$ century. The monasteries and convents were filled by monks with no religious vocation and surrounded by many servants. The main cause was the imposibility for the ruling classes to maintain their social position when they had large families. The arbitristas denounced the danger of depopulation and, with even more clearsightedness, the risk that the Viceroyalty's wealth should fall into the hands of the clergy.

PALABRAS CLAVE: Lima, Colonia, Iglesia, Clero regular, Economía. 